\title{
A Representação da Deficiência em Livros Infantis: séculos XIX e XX
}

\author{
Ann Dowker' \\ 'University of Oxford, Oxford - Inglaterra
}

\begin{abstract}
RESUMO - A Representação da Deficiência em Livros Infantis: séculos XIX e XX. O presente artigo analisa a representação de personagens deficientes em livros britânicos e norte-americanos do século XIX ao início do século XXI. São analisados tanto os assim chamados clássicos infantis quanto livros fora de edição ou não tão disponíveis. Uma das conclusões é que a representação de personagens deficientes geralmente é mais complexa e variada nos livros mais antigos. Além disso, segundo a visão de muitos autores do século XIX e início do século XX, é necessário aceitar infortúnios como uma forma de obediência a Deus, mas também porque, em última análise, eles são considerados um bem. Portanto, em muitos livros, a deficiência e sua cura, quando ocorre, estão associadas com o caráter.

Palavras-chave: Literatura infantil. Personagens com Deficiência. Escola do Sofrimento.
\end{abstract}

ABSTRACT - The Representation of Disability in Children's Literature: 19th and 20th Centuries. This article examines the treatment of disabled characters in British and North-American children's classics and in books that are out-of-print or less available to children from the $19^{\text {th }}$ century to early $20^{\text {th }}$ century. One of the main findings of this article is that the treatment of disabled characters is often more complex and varied in the latter than in the former. Moreover, the prevailing view of many $19^{\text {th }}$ century and some early $20^{\text {th }}$ century authors was that one should submit to misfortunes, both as a form of obedience to God's will, and because these seeming misfortunes are ultimately intended for one's own good. Therefore, in many books, disability, where it occurs, and its cure are associated with character. Keywords: Children's Literature. Disabled Characters. School of Pain.

Educação \& Realidade, Porto Alegre, v. 38, n. 4, p. 1053-1068, out./dez. 2013.1053 Disponível em: <http://www.ufrgs.br/edu_realidade> 
A Representação da Deficiência em Livros Infantis

Ao longo do século XIX e início do século XX, os clássicos da ficção infantil ${ }^{1}$ apresentam vários personagens com deficiências permanentes e temporárias: por exemplo, Clara, em Heidi (1872), escrito por Johanna Spyri²; Katy e a prima Helen, no livro What Katy Did (1872)*3, de Susan Coolidge; Colin, no livro The Secret Garden $(1911)^{* 4}$, de Frances Hodgson Burnett; Pollyanna, no livro Pollyanna (1911)*, de Eleanor Porter ${ }^{5}$; além de Tiny Tim, da famosa obra de Charles Dickens, $\mathrm{A}$ Christmas $\mathrm{Ca}$ rol $(1843)^{6}$ (que não é um livro infantil em sentido restrito, embora seja frequentemente considerado como tal).

Os livros normalmente considerados clássicos literários constituem um conjunto relativamente reduzido - e eu pretendo argumentar que esse conjunto também é pouco representativo - em relação às demais obras que abordam a temática da deficiência. Ao longo do século XIX e início do século XX, foram publicados muitos outros livros britânicos para crianças e jovens incluindo personagens com deficiências. Por exemplo, Charlotte Yonge, uma das mais famosas escritoras de obras juvenis na era vitoriana - e não menos conhecida hoje em dia -, incluiu inúmeros personagens com deficiências físicas em seus romances, tais como Margaret May, em The Daisy Chain; Geraldine Underwood, em The Pillars of the House; Charles Edmonstone, em The Heir of Redclyffe, $\mathrm{e}$ Ermine Williams, em The Clever Woman of the Family. Além disso, seus livros também incluem alguns personagens com deficiência intelectual, tais como Theodore Underwood, em The Pillars of the House, e Maria Fulmort, em Hopes and Fears.

Havia também muitos personagens deficientes nas histórias de escola ${ }^{7}$ para meninos do século XIX, como, por exemplo, Hugh Proctor, em The Crofton Boys, escrita por Harriet Martineau; Tony Pembury, em The Fifth Form at St. Dominics, escrita por Talbot Baines Reed, e também em histórias fantásticas, como The Little Lame Prince, escrita por Dinah Mulock. Escritores norte-americanos dessa época também incluíram personagens deficientes em vários de seus livros, alguns dos quais ainda hoje são muito conhecidos, enquanto outros caíram no esquecimento. Alguns exemplos são Dick e Billy, no romance Little Men*, de Louise Alcott; Raff Brinker, em Hans Brinker or the Silver Skates*, de Mary Mapes Dodge ${ }^{8}$; e - talvez o mais importante de todos - Katy e sua prima Helen, em What Katy Did*, de Susan Coolidge.

O modo como a deficiência é representada na ficção do século XIX é bastante complexo. Algumas personagens são retratadas de forma plana ${ }^{9}$, como vilões ou, mais frequentemente, como sujeitos dignos de pena. Porém, muitos personagens são relativamente redondos, e sua presença nos livros daquela época pode estar apontando para o fato de que a deficiência era percebida como uma parte comum da vida.

Conforme a maior parte dos críticos literários do final do século XX e início do século XXI, que discutem os primeiros livros infantis, personagens deficientes retratados em obras publicadas antes da Primeira Guerra Mundial geralmente são construídos a partir de estereó-

1054 Educação \& Realidade, Porto Alegre, v. 38, n. 4, p. 1053-1068, out./dez. 2013 Disponível em: <http://www.ufrgs.br/edu_realidade> 
tipos bidimensionais. Por vezes, aparecem como vilões, especialmente em livros com endereçamento predominante para adultos, mas também em algumas histórias fantásticas, como o Capitão Gancho de $P e$ ter Pan (originalmente Peter and Wendy, 1911), escrita por J. M. Barrie. Com mais frequência, contudo, esses personagens são representados como inválidos santos. Podem iniciar dessa forma ou se transformar nisso porque a experiência da deficiência foi capaz de transformá-los. A maioria desses inválidos santos ou reformados são meninas, sendo que elas raramente se tornam adultas: ou morrem muito cedo ou experimentam uma cura milagrosa.

Certamente, alguns dos primeiros livros infantis não se enquadram nessa descrição. Além disso, existem certas diferenças entre o tratamento concedido aos deficientes nos clássicos infantis e em livros que estão fora de edição ou que são menos disponíveis para as crianças. $\mathrm{O}$ tratamento dos personagens deficientes geralmente é mais complexo e variado nestes últimos do que nos primeiros. Nos primeiros livros, de forma geral, a exata natureza física bem como a causa da deficiência permanecem frequentemente obscuras. E isso indubitavelmente reflete a relativa falta de conhecimento médico durante o século XIX, mas também pode estar apontando, em vários casos, para uma ênfase maior nas consequências emocionais e espirituais da doença, do ferimento ou da deficiência, em detrimento do realismo físico. A natureza da deficiência é explicitada em dois casos nos quais as crianças precisam passar pelo processo de amputação de um pé: em The Crofton Boys (1841), de Martineau, o pé do personagem Hugh Proctor é esmagado em um acidente, ao passo que a personagem Geraldine Underwood, em The Pillars of the House (1873, de Yonge), é submetida a uma cirurgia drástica para curála de uma doença muito séria, presumivelmente tuberculose óssea. Na maioria dos casos, contudo, os personagens são simplesmente descritos como aleijados ou então tiveram alguma forma não específica de ferimento acidental na coluna. Quanto há alguma tentativa de fornecer explicações médicas, ocorre uma ênfase na inflamação da área do ferimento. Contudo, talvez não seja nem mesmo adequado tentar interpretar a maioria dessas histórias à luz do realismo médico. A falta de especificidade médica nesses livros tem o efeito de facilitar tratamentos altamente improváveis e estilizados da deficiência. Por outro lado, também evita que o personagem deficiente seja reduzido a uma condição médica específica.

Em muitos livros, a deficiência e a sua cura, quando ocorre, estão associadas ao caráter. Em alguns livros, a cura é o resultado direto de uma atitude mais saudável em relação à vida, frequentemente implicando uma renúncia voluntária ao papel de deficiente. O personagem Colin, em The Secret Garden (1911), de Burnett, por exemplo, foi comprometido emocionalmente, passando toda a sua infância entre quatro paredes e convencido pelos criados e por um médico de que seu destino é ser um corcunda, tal qual seu pai, e morrer cedo. Em última análise, Colin é curado através de uma combinação de amizades saudáveis

Educação \& Realidade, Porto Alegre, v. 38, n. 4, p. 1053-1068, out./dez. 2013. 1055 Disponível em: <http://www.ufrgs.br/edu_realidade> 
A Representação da Deficiência em Livros Infantis

com Mary e Dickon, da exposição aos efeitos curativos da natureza e do mundo exterior, além da convicção de que ele é, na verdade, saudável e “[...] viverá para todo o sempre" (Burnet, 1911, p. 267). No caso de Colin, torna-se claro para o leitor que sua doença é histérica: possui causas emocionais e não físicas. Entretanto, em alguns livros, os efeitos de um ferimento de motivação claramente física são curados através da força de vontade, como, por exemplo, quando a personagem Clara, de Johanna Spyri (Heidi, 1880), descobre que é capaz de andar depois que Peter (em uma atitude maliciosa) empurra sua cadeira de rodas no precipício.

Mais frequentemente, contudo, a deficiência não é curada simplesmente através de uma mudança de atitude emocional. Antes, ela é um meio de disciplina espiritual (verificar o livro de Lois Keith, Take Up Thy Bed and Walk, 2001). Uma criança teimosa, frequentemente uma menina com comportamento de menino, sofre algum ferimento, via de regra devido à sua imprudência ou desobediência e, assim, aprende a ter disciplina ao longo de semanas ou meses de sofrimento e relativa imobilidade. O exemplo mais conhecido encontra-se na obra What Katy Did (1872)*. Caracterizada como uma menina espirituosa e obstinada, Katy cai de um balanço no qual tinha sido proibida de brincar. Na queda, sofre um ferimento na coluna e fica impossibilitada de andar durante anos, recuperando-se, por fim, de forma quase milagrosa. Sua prima Helen, que é uma deficiente permanente devido a um acidente sofrido há alguns anos, afirma que Deus lhe concedera a chance (assim como à própria Helen) de estudar na Escola do sofrimento, onde ela poderá aprender lições através da paciência e da alegria, “[...] tirando o melhor proveito de tudo" e "[...] tornando-se o coração do lar" (1907, p. 125). Um tema relativamente semelhante encontra-se em inúmeros outros livros, tal como Jack and Jill (1879)*, de Alcott ("Essas costas um pouco doloridas serão uma espécie de consciência para lembrá-la do que você deveria e do que não deveria fazer, e, desse modo, você estará aprendendo a obediência”) e também está presente em Daisy's Dilemmas (1900), de Hart. Em Pollyanna (1911)*, de Porter, a deficiência temporária não é considerada uma disciplina para a própria Pollyanna (pois ela já é bondosa), mas para sua tia, vários amigos e vizinhos.

Alguns personagens com deficiências permanentes nos livros infantis escritos no século XIX e início do século XX são inválidos santos, cuja principal função parece ser a de servir como modelos para os demais. Alguns exemplos incluem Tiny Tim, em A Christmas Carol (1843), de Dickens, Carol, em The Birds' Christmas Carol (1891)*, de Wiggin, Dick, em Little Men (1871)*, de Alcott, e Lucinda Snow, cuja história é contada como uma inspiração para Jill, em Jack and Jill (1879)*, de Alcott. Lucinda, apesar de, ou talvez por causa de sua ausência - na verdade, nós nunca a encontramos, pois se presume que ela tenha morrido algum tempo antes de iniciar a história - é um exemplo nítido dessa representação. Ela ficou acamada durante toda a sua vida como resultado de uma queda ocorrida quando era uma jovem garota, e a Senhora Minot conta essa história como uma inspiração para Jill, que também é

1056 Educação \& Realidade, Porto Alegre, v. 38, n. 4, p. 1053-1068, out./dez. 2013. Disponível em: <http://www.ufrgs.br/edu_realidade> 
incapaz de caminhar devido a um ferimento nas costas (apesar de que, no final, Jill é curada):

Conheci essa Lucinda por vários anos e, embora inicialmente eu achasse que o seu destino era o mais triste que poderia haver, acabei percebendo, por fim, o quão feliz ela era apesar de sua aflição, e quão bondosa, útil e amada... Ela era tão paciente que outras pessoas ficavam com vergonha de reclamar de suas pequenas preocupações; tão alegre que ela própria ficava mais leve; tão diligente que era capaz de fazer amigos e dinheiro através dos belos trabalhos que realizava; e, o melhor de tudo, tão sábia e doce que ela parecia tirar o melhor de tudo e transformar o seu próprio espaço em uma espécie de capela aonde as pessoas iam em busca de conforto, conselho e um exemplo de vida piedosa (Alcott, 1898, p. 81).

O exame atento da função de personagens deficientes nos primeiros livros infantis revela, entretanto, um pano de fundo mais complexo. Em primeiro lugar, a Escola do sofrimento não faz distinções de gênero. Tanto os meninos quanto as meninas crescem, aprendem e se tornam disciplinados através do sofrimento. Hugh, em The Crofton Boys (1841), e Leonard, em The Story of a Short Life (1885), de Ewing, são ótimos exemplos de aprendizagem quanto ao controle do temperamento e da alegria. Ferdy, em The Oriel Window (1896), de Molesworth, cujo temperamento já é controlado, usa seu período de sofrimento para aprender a realizar boas obras na comunidade.

A principal diferença quanto ao tratamento de meninas e meninos é que existe uma ênfase maior para que as meninas aprendam a ser úteis em suas famílias, enquanto os meninos precisam desenvolver e demonstrar coragem: certamente, não se trata de uma diferença restrita a livros de personagens deficientes. Em The Story of a Short Life (1885), de Ewing, Leonard inicialmente reage à dor e à deficiência causada por seu ferimento na coluna, tornando-se rabugento e irritadiço; por vezes, chega a apelar para violência física, batendo em um empregado com sua muleta. No entanto, ele acaba suportando bravamente seu sofrimento, em parte devido às exortações de sua mãe, que lhe diz que, embora ele não possa se tornar um bravo soldado, poderá se tornar "um bravo aleijado" (1885, p. 48). A mensagem transmitida é praticamente a mesma que Erwin havia formulado em Convalescence (1883), uma história em versos: "A coragem que ousa e a coragem que suporta são, na verdade, a mesma e única” ( 1895, p. 96).

Além disso, a Escola do sofrimento não se limita à questão da deficiência, cuja representação deve ser analisada em um contexto mais amplo, a partir do qual os infortúnios eram vistos como enviados por Deus enquanto um bem irrevogável para o indivíduo. A literatura infantil do século XIX frequentemente enfatiza que infortúnios aparentes devem ser aceitos como parte de um plano superior: essa atitude é expressa de forma resoluta em Rabbits' Tails, uma pequena história que faz parte do

Educação \& Realidade, Porto Alegre, v. 38, n. 4, p. 1053-1068, out./dez. 2013. 1057 Disponível em: <http://www.ufrgs.br/edu_realidade> 
A Representação da Deficiência em Livros Infantis

livro Aunt Judy's Tales (1859), de Gatty, na qual o narrador afirma o seguinte a respeito de dois jovens órfãos: "Se de fato fosse o correto para as crianças que sua mãe estivesse viva, ela não teria sido levada” (2007, p. 112). Esse mesmo livro também inclui o conto Grandmamma's Throat, cuja temática é mais a doença do que propriamente a deficiência em seu sentido usual. No final da história, a vovó permanece viva e com boa saúde pelo menos até os noventa anos de idade, embora sua infância e juventude tenham sido ofuscadas e limitadas por problemas na garganta. Ela não sofria apenas devido aos ataques da verdadeira dor causada pela doença, mas também devido às limitações causadas em sua vida pela necessidade de ir cedo para a cama, evitar sair no mau tempo e, inclusive, evitar esforço mental. A questão central da história é que

[...] nós somos frequentemente guiados pelo Todo Poderoso de um modo que nós acreditamos não ser tão bom para nós. Nosso caráter é formado da maneira como Ele gostaria, através de circunstâncias que parecem, em si mesmas, um empecilho para qualquer tipo de evolução; nós nos tornamos inclusive mais úteis para o próximo quando toda a força de nossa utilidade nos parece ter sido tirada (1862, p. 132).

Até mesmo os sofrimentos de um bebê podem ser vistos como uma disciplina espiritual. Em Heartsease (1854), de Yonge, a jovem mãe de um delicado bebê prematuro recebe o seguinte consolo de seu cunhado: "Alguém que chega a amá-lo mais do que você mesma é capaz... pode estar disciplinando-o para a vida futura ou tornando-o apto para a mais brilhante glória” (1855, p. 193).

Assim sendo, para os escritores do século XIX, a aceitação de uma saúde frágil e da deficiência, assim como de outros infortúnios, frequentemente era vista como parte da aprendizagem em aceitar a vontade de Deus com relação a todos os aspectos da vida. A personagem Katy, de Susan Coolidge, por exemplo, entende, no final da narrativa, que "[...] havia Amor no Sofrimento. Eu percebo isso agora. Quão bondoso tem sido para mim o Querido Professor!” (1907, p. 186). Em The Crofton Boys, de Harriet Martineau, Hugh é devastado pelo pensamento de que a perda de seu pé significa que ele jamais realizará seus sonhos de se tornar um soldado ou um marinheiro para viajar ao redor do mundo. Sua mãe lhe relata sobre outras pessoas que sofreram golpes semelhantes: Richard Grant, o marceneiro que perdera a agilidade da mão; Huber, o naturalista que ficara cego; Beethoven, que ficara surdo. Além disso, ela também comenta o seguinte:

Você diria que eles foram tratados de forma severa? Ou você suporia que seu Pai lhes concedeu algo maior e melhor para fazer do que aquilo que haviam planejado para si mesmos?... Não há dúvida de que seus corações muitas vezes aumentavam em seus peitos por causa de suas decepções: mas eu creio inteiramente que logo eles percebe-

1058 Educação \& Realidade, Porto Alegre, v. 38, n. 4, p. 1053-1068, out./dez. 2013. Disponível em: <http://www.ufrgs.br/edu_realidade> 
ram que a vontade de Deus era mais sábia do que os seus próprios desejos... Logo eles passaram a sentir um prazer novo e delicioso, que só pode ser sentido por aqueles que se decepcionaram amargamente... O prazer de elevar as suas almas para suportar a dor e concordar silenciosamente com Deus [...] (1856, p. 114-115).

Alguns escritores levaram adiante essa concepção até os primeiros anos do século XX. Em A Schoolgirl's Battlefield (1910), de Raymond Jacberns, a personagem Elsa, uma menina dotada de enorme talento artístico, sofre de uma doença ocular que, durante algum tempo, ameaça torná-la completamente cega, causando-lhe graves problemas de visão. Devido às restrições médicas quanto ao uso dos olhos, ela é obrigada a abandonar completamente suas atividades de pintura. A tia de uma amiga, Senhora Compton, profere as seguintes palavras:

Você não deve pensar que eu sou indelicada, pequena Elsa, quando lhe digo que você está se esquivando de tomar seu lugar no campo de batalha do Rei... Nosso Rei nos trouxe para este mundo para realizarmos um certo trabalho. Todos nós recebemos uma tarefa específica que deve ser feita para Ele, e alguns de nós parecem ter recebido tarefas mais difíceis para desempenhar do que outros... Deus tem trabalho para nós em Seu próximo mundo, mas também neste, e, portanto, não é difícil e tampouco injusto que Ele tenha decidido nos treinar para que nós externemos aquilo que de melhor temos em nós mesmos para o Seu trabalho. Elsa, você tem esperança à sua frente e não desânimo. Sucesso e não fracasso. Há algo na vida que deve ser feito por você, que só você pode fazer e que lhe renderá, mais cedo ou mais tarde, a palavra 'Parabéns' (Jacberns, 1910, p. 383-384).

Elsa acaba aceitando alegremente sua deficiência e suas restrições, mudando, com sucesso, da pintura para a escrita de histórias e a modelagem. O livro encerra da seguinte maneira: "Ela aceitou seu lugar na vida; ela está fazendo o melhor que pode nesse lugar; e, fazendo o seu melhor, ela descobriu que a felicidade pode ser encontrada até mesmo em um campo de batalhas" (Jacbern, 1910, p. 387).

Assim sendo, o ponto de vista predominante de muitos autores do século XIX e de alguns autores do início do século XX é a necessidade de submissão aos infortúnios enquanto uma forma de obediência à vontade de Deus; tais infortúnios aparentes, em última análise, são enviados para o nosso próprio bem. Principalmente em alguns livros do início da era vitoriana, essa atitude é capaz de conduzir o comportamento das personagens a patamares extremos. Em The Two Guardians, de Yonge, por exemplo, Marian não tem certeza se deve realmente extrair um dente, mas acaba decidindo que sim, com base no seguinte raciocínio: "A abnegação é sempre o melhor e, em caso de dúvida, é sempre mais seguro optar pelo mais desagradável" (Yonge, 1871, p. 127).

Educação \& Realidade, Porto Alegre, v. 38, n. 4, p. 1053-1068, out./dez. 2013. 1059 Disponível em: <http://www.ufrgs.br/edu_realidade> 
A Representação da Deficiência em Livros Infantis

Essa ênfase na submissão à vontade de Deus é válida para todos os personagens e pode ser percebida em uma ampla gama de circunstâncias: não apenas no caso da deficiência. A necessidade desse tipo de submissão é certamente um traço forte quanto ao tratamento concedido aos personagens deficientes, mas não chega a distingui-los dos demais: amigos e irmãos de personagens deficientes também precisam se submeter à vontade de Deus. Em The Daisy Chain (1856), de Yonge, por exemplo, Margaret é obrigada a aceitar tanto sua invalidez quanto a perda de esperança em se casar, mas sua irmã Ethel também renuncia a qualquer possibilidade de casamento, além de aceitar os ensinamentos disciplinares impostos pelo seu sexo: impossibilidade de se realizar intelectualmente e tampouco de desempenhar as obrigações de mulher. Para garantir sua autoestima, a irmã de ambas, Flora, precisa aprender a disciplina espiritual de um modo ainda mais dolorido, quando seu bebê morre devido à falta de cuidado por parte de uma babá a quem Flora o havia confiado.

Em terceiro lugar, personagens deficientes nem sempre são tratados como criaturas indefesas, dignas de pena, ou como santos inválidos. A Escola do sofrimento não é apenas co-educacional como também é abrangente ${ }^{10}$ ! De fato, alguns personagens deficientes se definem por outras características além de sua deficiência, tais como alguns talentos especiais. A personagem Geraldine Underwood, no livro The Pillars of the House (1873), de Young, e a personagem Ermine Williams, em outro livro de Young intitulado The Clever Woman of the Family (1865), embora apresentem personalidades distintas em vários aspectos, são ambas mulheres inteligentes, sensíveis e dotadas de grandes talentos: no caso de Geraldine, um talento artístico e, no caso de Ermine, um talento literário. Seus dons criativos, associados à sua sensibilidade emocional, recebem um destaque mais acentuado do que suas deficiências (Sobre esse assunto, verificar também Holmes, 2004). O menino aleijado Tony Pembury, na obra de Reed chamada Fifth Form at St Dominic's (1887), é inteligente, espirituoso e frequentemente sarcástico, além de fazer uso de seus talentos retóricos para conquistar influência e poder no universo do internato masculino.

Personagens com deficiência também são capazes de demonstrar falhas humanas. Apesar de o herói do livro Sidney Grey (1857), de Keary, poder ser classificado muito bem na categoria dos santos inválidos, Keary também constrói vários personagens dotados de elevada complexidade. Por exemplo, Louis, em Mia and Charlie (1856), é representado como inteligente, corajoso e esperto, embora também de pavio curto e irritadiço. E a filha do oficial de justiça, no livro Father Phim (1875), do mesmo autor, também é quase tão desagradável e mal-humorada quanto o seu próprio pai (não deficiente), mas pode ser afetiva por vezes. Daisy, em Daisy's Dilemmas (1900), de Hart, não é apenas obstinada e feroz, mas também mal educada, egoísta e, em várias situações, uma valentona. De certo modo, trata-se de uma história vinculada à tradição

1060 Educação \& Realidade, Porto Alegre, v. 38, n. 4, p. 1053-1068, out./dez. 2013 Disponível em: <http://www.ufrgs.br/edu_realidade> 
da Escola do sofrimento, mas a lesão que Daisy possui na espinha não chega, sozinha, a reformá-la e sim, a consciência que ela vai adquirindo quanto à gentileza demonstrada pelas pessoas que ela havia maltratado anteriormente.

Em quarto lugar, personagens deficientes não morrem ou são curados, invariavelmente. Muitos são curados apenas de forma parcial, ou sobrevivem com uma deficiência levemente inalterada ou severa, o que, em muitos casos, não os impede de levar vidas interessantes e de seguir suas carreiras. Por exemplo, a perna coxa do personagem Tony Pembury, de Reed, não o impede de ser editor de um jornal nacional, sendo que "[...] todos querem ter um bom relacionamento com um editor" (1887, p. 460). A perda de um pé, por parte da personagem Hugh Proctor, de Martineau, significa que ele não poderá se tornar um soldado ou um marinheiro, mas, ainda assim, ele realiza sua ambição original de "viajar ao redor do mundo" (1856, p. 113) quando se junta ao Serviço Civil Indiano. O mais impressionante de tudo é o desfecho da história de Dinah Mulock, em Little Lame Prince and His Travelling Cloak (1875), uma fantasia um tanto alegórica com final bastante realista. O príncipe derrota seus inimigos e de seu país, sendo restaurado ao trono. Sua paralisia "[...] nunca é curada" (1909 edition, p. 115), o que não o impede de ser um rei extremamente respeitado e repleto de sucesso, estabelecendo muitas reformas importantes, inclusive a abolição da pena de morte.

Assim, o tratamento da deficiência no século XIX e início do século XX, na literatura infantil, é mais complexo do que aparenta à primeira vista. Embora a deficiência seja de fato considerada - como todos os infortúnios e dificuldades - como fonte de disciplina espiritual, personagens deficientes nem sempre eram completamente transformadas em estereótipos de santos inválidos. Em parte, isso pode estar refletindo diferenças históricas e geográficas, ou traços específicos dos escritores e suas próprias e vicárias experiências com a deficiência. O mesmo autor pode lidar de modos muito distintos com personagens deficientes em livros diferentes.

É interessante notar que a representação de personagens deficientes enquanto santos inválidos, ou enquanto meninas teimosas que são domadas pela disciplina e pelo sofrimento, parece prevalecer mais nos livros ainda em edição do que naqueles que já não são mais publicados há muito tempo. Os livros do século XIX que ainda são publicados hoje em dia não revelam apenas as atitudes dos autores e leitores do século XIX, mas também as atitudes de leitores tardios em função dos quais esses livros ainda são reeditados. Em última análise, as representações do santo inválido e da menina teimosa a ser domada são uma exigência dos leitores da metade e final do século XX tanto quanto foram uma exigência de leitores do século XIX.

Explicações para esse fenômeno são especulativas, mas, ainda assim, podemos considerar duas razões possíveis. Uma delas é que

Educação \& Realidade, Porto Alegre, v. 38, n. 4, p. 1053-1068, out./dez. 2013. 1061 Disponível em: <http://www.ufrgs.br/edu_realidade> 
A Representação da Deficiência em Livros Infantis

aquilo que foi iniciado a partir de temas religiosos ou sociais na ficção do século XIX frequentemente acabou sendo incorporado por autores tardios devido aos seus valores sentimentais. Um exemplo paralelo, que ocorreu um pouco antes, está relacionado com as cenas retratando a iminência do leito de morte ou a própria morte na cama, utilizadas com fins religiosos em livros pré-vitorianos ou em livros do início da era vitoriana. Essas cenas foram aparentemente incorporadas por escritores do final da era vitoriana apenas como uma estratégia para levar os leitores às lágrimas (Avery, 1965). Outra explicação possível está relacionada com as narrativas sobre vidas nos subúrbios e na pobreza, utilizadas por escritores da metade do período vitoriano, tais como Charles Dickens e Hesba Stretton, com a finalidade de expor os males sociais e morais, mas que parecem ter sido utilizadas por alguns escritores, mais tarde, com finalidades mais puramente sentimentais (Bratton, 1981). Nesses casos, o contexto mais amplo dentro do qual o tema específico havia sido produzido deixa de existir; isolado de seu contexto, esse tema pode se tornar quase uma caricatura de si próprio.

Outra razão pode estar relacionada à própria questão da deficiência. No século XIX, deficiências temporárias e permanentes eram comuns e podem ter diferido apenas de modo sutil em relação às doenças frequentes que acometiam muitas pessoas. Embora pessoas deficientes, em todos os períodos da história, frequentemente tenham sido tratadas - de forma suspeita ou condescendente-como diferentes, é possível que, no século XIX, a deficiência tenha sido considerada mais como uma parte da condição comum do que passou a ser mais tarde. No século XX, possivelmente as deficiências passaram a ser vistas como mais passíveis de tratamento e prevenção, pelo menos no caso dos jovens; além disso, tornou-se mais apropriado - ou, pelo menos, mais possível - confinar as pessoas com deficiências em instituições. Assim, personagens deficientes passaram a ser vistas como mais raras ou mesmo anormais, o que exigia a santidade incomum ou uma cura miraculosa para justificar sua presença. Além disso, é possível que a ênfase em atividades saudáveis e alegres ao ar livre, em alguns livros infantis britânicos da metade do século XX, tenham a tendência de excluir pessoas deficientes ou mesmo personagens delicados, que eram tão comuns no período anterior. A rejeição ao didatismo bem como ao sentimentalismo do século XIX pode ter contribuído para a tendência a jogar fora o bebê juntamente com a água da banheira, devido à insistência de que os personagens principais das histórias fossem alegres, saudáveis e extrovertidos. De fato, poucos livros infantis publicados entre aproximadamente 1925 e 1965 parecem incluir personagens deficientes, comparados aos livros publicados antes ou depois desse período.

Talvez ambas essas razões possam explicar o fato de que alguns livros infantis da metade do século XX que ainda abordavam doenças crônicas e deficiência pareçam mais duros e mais punitivos em suas abordagens do que os livros do século XIX. A temática da Escola do sofrimento foi levada adiante nesses livros tardios; no entanto, enquanto o

1062 Educação \& Realidade, Porto Alegre, v. 38, n. 4, p. 1053-1068, out./dez. 2013. Disponível em: <http://www.ufrgs.br/edu_realidade> 
aspecto punitivo, nesses livros, tende a ser mais enfatizado, há uma ênfase muito menor sobre o contexto mais geral da submissão a Deus. Doenças graves e deficiências temporárias ou de longa duração deixaram de ser vistas como uma forma de desenvolver uma feliz subserviência à vontade divina; elas também deixaram de ser vistas como parte do cotidiano; mas, ainda assim, continuaram sendo usadas, por vezes - talvez devido à influência de livros mais antigos - como um veículo de enredo para o desenvolvimento das personagens. Talvez essa seja a razão pela qual elas aparentemente eram utilizadas, às vezes, de forma mais direta como punição, se comparadas com os livros do período vitoriano, que supostamente seria mais severo.

Dois autores que fizeram uso frequente desse tipo de temática foram Elinor Brent-Dyer e Enid Blyton. A abordagem de Brent-Dyer é mais semelhante àquela encontrada em autores do século XIX. Por vezes, há uma sugestão de que a saúde delicada seja, em si mesma, capaz de levar à virtude moral: notadamente no caso de Robin Humphries, personagem da série de livros de escola Chalet $^{11}$. Porém, os dois exemplos mais notáveis, em seus livros, são os personagens desviantes que acabam sendo reformados através da disciplina imposta pelo ferimento: a personagem Eustacia, em Eustacia Goes to the Chalet School (1930), bem como Marigold, em Stepsisters for Lorna (1948).

No primeiro livro, Eustacia é criada em casa por seus pais, que são intelectuais; ela não possui qualquer experiência de socialização, tornando-se pedante e egocêntrica. Ao ser enviada à Escola Chalet por uma tia que não consegue lidar com seu comportamento difícil e excêntrico, logo ela entra em conflito com as demais meninas. Ela não procura se adaptar, comete o pecado capital de contar histórias e, em sua busca frenética por livros e um lugar silencioso para lê-los, desobedece às regras escolares de forma flagrante. No final, sua infelicidade a leva a fugir. Quando já se encontra fora, na encosta das montanhas, ela distende as costas e passa semanas, inicialmente, acamada e, depois, em uma cadeira de rodas. Durante seu período de convalescência, ela se arrepende de seu comportamento antissocial e voluntarioso; então, torna-se amiga de Joey, que antes era seu antagonista, além de sinalizar o fim de seu pedantismo ao permitir que seu nome seja encurtado para Stacie.

No último livro, Stepsisters for Lorna, a personagem Lorna é forçada, inesperadamente, a dividir seu lar, no qual vive com a tia, com duas meias-irmãs desconhecidas. Isso ocorre quando sua mãe, quase sempre ausente, casa-se novamente e resolve que suas enteadas precisam ir à escola na Inglaterra, enquanto ela própria permanece com seu marido doente na ilha de Madeira. Esses acontecimentos recaem repentinamente sobre as três meninas, que, evidentemente, encontram dificuldade em se adaptar. Rosemary é bem intencionada e responsável, embora por vezes não tenha muito tato; mas Marigold é mimada, egoísta, voluntariosa e com tendência a acessos de raiva. No final, ela

Educação \& Realidade, Porto Alegre, v. 38, n. 4, p. 1053-1068, out./dez. 2013. 1063 Disponível em: <http://www.ufrgs.br/edu_realidade> 
A Representação da Deficiência em Livros Infantis

desobedece à regra de não andar de bicicleta em uma ladeira bastante íngreme, cai e machuca as costas (Há, aqui, um paralelo explícito com a história de Susan Coolidge, What Katy Did). Inicialmente, ela é mantida em um hospital, com um molde de gesso, e então fica acamada em casa.

Torna-se bastante evidente, na história, que essa experiência deveria discipliná-la quanto ao seu comportamento mimado. Esse efeito não deve ser atingido apenas através da dor física e das restrições, mas também pelo fato de ela ficar nas mãos de uma senhora rígida no hospital: "Aquela senhora não tinha tempo para gritos histéricos e ataques de fúria de bebês, e sua disciplina era afiada. Se Marigold não se comportasse adequadamente, sua cama era colocada para fora [...] (Em uma ocasião, a matrona chega a esbofeteá-la) [...] O médico afirmou que mais um ou dois meses de hospital e aquela senhora iria torná-la uma menina muito mais agradável de se conviver" (Brent-Dyer, 1948, p. 176).

Infelizmente, as camas precisaram ser utilizadas devido a um acidente de trem, e Marigold é enviada para casa mais cedo. Sua tia precisa discipliná-la e evitar que ela se torne um incômodo excessivo para a prima e a irmã; o médico intervém, quando necessário, com uma combinação de sedativos e ameaças de chicoteadas. Ele resume todo o episódio para ela: "De fato, a seu tempo, você voltará a andar. Mas meninas que desobedecem ordens [...] devem esperar punição. Nesse caso, você não puniu a si mesma [...] Eu concordo que seja um preço muito alto, mas isso é o que acontece quando se tenta roubar a alegria das demais pessoas" (Brent-Dyer, 1948, p. 224). De forma pouco convincente, a história termina com o início da transformação de Marigold, que ocorre no dia de Natal, enquanto o espírito natalino também inspira melhores sentimentos aos demais.

Esse livro foi discutido com alguma profundidade porque incorpora todas as atitudes mais severas da Escola do sofrimento, deixando totalmente de fora qualquer aspecto mais suave. Oitenta anos depois de What Katy Did, a atitude aqui é muito mais autoritária. Em What Katy Did e em outros livros do século XIX, uma das questões centrais é o triunfo da personagem ferida sobre a adversidade, além da sua aceitação, o que contribui para sua própria evolução espiritual. Em 1948, Marigold é punida principalmente através de disciplina externa: ela "[...] puniu a si mesma" (1948, p. 136), mas as autoridades médicas - como a matrona do hospital e o médico - também são agentes de punição. Até o final pouco convincente, não há qualquer evidência de que Marigold seja uma participante ou de que possa se tornar, sozinha, uma participante capaz de triunfar em direção à própria evolução espiritual. A disciplina é imposta de fora. Perdemos o contexto da ênfase sobre a aceitação dos desígnios de Deus, característica do século XIX, e ficamos apenas com o conceito do ferimento enquanto uma punição.

Para ser justo, esse traço extremo não é característico de BrentDyer. Outros personagens, tais como Eustácia, são representados como participantes mais cooperativos em relação à sua própria transforma-

1064 Educação \& Realidade, Porto Alegre, v. 38, n. 4, p. 1053-1068, out./dez. 2013. Disponível em: <http://www.ufrgs.br/edu_realidade> 
ção. Parte da diferença provém do fato de que Brent-Dyer obviamente não gosta de Marigold e a enxerga exclusivamente de um ponto de vista externo. Embora ela também desaprove grande parte das atitudes de Eustácia, parece ter mais simpatia por essa personagem (que autor ou rato de biblioteca poderia não ter alguma simpatia por um personagem desesperado em encontrar algo para ler?!). O livro sugere uma degeneração da Escola do sofrimento ao longo dos anos, que abandona a escola teológica em favor da casa de correção $0^{12}$.

Enid Blyton apela para uma abordagem um tanto diferente. Seu tema recorrente não é tanto a questão de uma personagem geralmente obstinada que precisa aprender disciplina e, sim, de uma criança talentosa cuja arrogância e a busca egoísta de seus próprios talentos têm, como resultado, a perda temporária desses talentos. Então, a menina precisa se redimir demonstrando preocupação e serviço em prol dos demais, podendo, dessa maneira, recuperar seus talentos. Há três exemplos nos livros de Malory Towers. Em Last Term at Malory Towers (1951), Amanda, uma exímia nadadora e atleta fisicamente forte, atreve-se a nadar em um lugar proibido no mar agitado. Ela machuca os músculos e é obrigada a parar de praticar esporte. Não fica claro se ela será capaz de retornar para as competições olímpicas, conforme havia planejado. Contudo, ela consegue resgatar seu próprio caráter e também seus propósitos esportivos ao treinar a aluna mais jovem June, brilhante porém difícil, para o sucesso desportivo. Em Third Year at Malory Towers (1948), Mavis, uma cantora dotada com uma voz adorável, foge para poder participar de uma competição de talentos. Ela fica presa no meio de uma tempestade, adoece com "[...] problemas na garganta e no peito [...]" (1948, p. 140) e acaba perdendo a qualidade de sua voz por vários meses. Ela recupera tanto a voz quanto suas esperanças profissionais, e a narrativa deixa claro que ela merece tal recuperação, uma vez que aprendeu a cooperar com os demais nas atividades escolares, além de não ter reclamado sobre sua voz. Em Upper Fourth at Malory Towers (1949), a escola da dor de Alicia é mais curta. Ela é academicamente inteligente, porém áspera e intolerante com pessoas menos inteligentes. Durante as provas finais, ela contrai sarampo e não consegue raciocinar adequadamente, sendo reprovada nos exames. Inicialmente, ela acredita que seu cérebro se tornou confuso. Após a recuperação, ela se torna mais tolerante em relação a pessoas intelectualmente mais vagarosas.

Certamente nem todos os livros da metade do século XX excluem a temática da deficiência temporária ou permanente. Tampouco é possível afirmar que todos tratam a deficiência como uma punição necessária para a evolução do caráter, da mesma forma como nem todos os livros do século XIX e início do século XX tratam personagens deficientes como santos inválidos que necessitam de curas milagrosas. Alguns ótimos exemplos de representações muito mais sutis de deficiência são, entre outros, os romances históricos de Rosemary Sutcliff, intitulados The Eagle of the Ninth (1954) ${ }^{13} \mathrm{e}$ Warrior Scarlet (1958). Nas histórias de

Educação \& Realidade, Porto Alegre, v. 38, n. 4, p. 1053-1068, out./dez. 2013. 1065 Disponível em: <http://www.ufrgs.br/edu_realidade> 
A Representação da Deficiência em Livros Infantis

escola St Brides, escritas por Dorita Fairlie Bruce, a personagem Winifred Arrowsmith, aluna e mais tarde secretária da escola, é um exemplo de personagem deficiente muito distante de uma caracterização unidimensional, embora seja interessante notar que o livro em que esta personagem tem sua atuação mais marcante, The Girls of St Brides (1923), é o primeiro da série, podendo ser considerado mais como do início do que da metade do século XX.

Entretanto, ao discutir a literatura do século XIX, é importante ter em mente que os livros daquele período que ainda hoje são muito conhecidos podem não constituir um conjunto representativo. Também é possível que esses livros tenham passado pelo filtro de atitudes tardias.

De forma geral, pois, é possível apontar continuidades e descontinuidades nas representações de pessoas deficientes nos livros para crianças do século XIX e até a primeira metade do século XX, sendo que tais aspectos parecem estar presos a contextos históricos e sociais específicos.

Recebido em 26 de março de 2013 Aprovado em 30 de setembro de 2013

\section{Notas}

1 Embora este artigo faça uma divisão entre os clássicos infantise os livros atualmente menos conhecidos, tais distinções podem ser feitas apenas de forma aproximada. Alguns livros que atualmente não são considerados clássicos infantis, na verdade, ainda são editados, embora para um público leitor quase exclusivamente adulto (por exemplo, The Fifth Form at St. Dominics', em 1971). Mais interessante, talvez, seja o caso da nova versão do livro de Rosemary Well The Little Lame Prince, em 1992, pela Picture Lions. A estrutura básica do enredo é um tanto semelhante ao original, mas a nova versão se transformou em um livro de imagens bem menor, endereçado a crianças pequenas. O texto é quase totalmente diferente, sendo que animais felpudos substituíram as personagens humanas (Nota da Autora - N. A.).

2 Obra com várias traduções e adaptações para o mercado editorial brasileiro, sob o mesmo título, por editoras como Melhoramentos, CEDIC, Hemus e Rideel, entre outras (Nota do Tradutor - N. T.).

3 Livros marcados com asterisco são de autores norte-americanos (ou, no caso do francês Hodgson Burnett, residentes de longa data nos Estados Unidos). Todos os demais são de autores ingleses (N. A.).

4 Obra com várias traduções e adaptações para o mercado editorial brasileiro, sob o título O Jardim Secreto, destacando-se a adaptação feita por Ana Maria Machado para a Editora Scipione. Há outras traduções, das editoras 34 e Rideel, sendo que, na edição da Editora Bestseller, ganhou o nome de O Jardim Encantado (N. T.).

5 Obra que recebeu várias traduções e adaptações para o mercado editorial brasileiro, através de editoras como Ática, Martin Claret e Ibep Jr., destacando-se a tradução feita por Monteiro Lobato para a Editora Nacional, já na década de 40. Tratava-se de leitura obrigatória para adolescentes brasileiras até a década de 70 (N. T.).

6 Obra que recebeu várias traduções e adaptações para o mercado editorial brasileiro, ora sob o título Canção de Natal ou Uma canção de Natal (editoras Companhia das Letrinhas e Caramelo), ora como Cântico de Natal (editoras Martin Claret e Verbo), ora como Um conto de Natal ou Conto de Natal (editoras Ediouro, Rideel e L\&PM) (N. T.).

1066 Educação \& Realidade, Porto Alegre, v. 38, n. 4, p. 1053-1068, out./dez. 2013. Disponível em: <http://www.ufrgs.br/edu_realidade> 
Dowker

7 School story, no original. Trata-se de um gênero literário muito popular na Inglaterra principalmente no final do século XIX e início do século XX. Suas principais características são uma ênfase em personagens pré-adolescentes representados no ambiente escolar, frequentemente caracterizado como escolas internas. Esse gênero normalmente se subdivide em histórias para meninos e para meninas (N. T.).

8 Obra que teve várias traduções e adaptações para o mercado editorial brasileiro sob o título Os patins de prata, pelas editoras Ediouro, Paulinas e Abril Cultural (N. T.).

9 A caracterização de personagens complexas como redondas e de personagens simples como planas refere-se à tipologia de E. M. Foster. Ver: Aspectos do Romance, da Editora Globo, 1969 (N. T.).

10 Em inglês, a autora faz um jogo com as expressões comprehensive school (escola secundária) e co-educational school (escola mista, frequentada por meninos e meninas) (N. T.).

11 A série de livros Chalet possui mais de sessenta livros escritos por Elinor BrentDyer e foi escrita entre 1925 e 1970. (N. T.).

12 Trata-se de uma referência metafórica ao parágrafo anterior, no qual a autora afirma que "[...] a disciplina é imposta de fora. Perdemos o contexto da ênfase sobre a aceitação dos desígnios de Deus, característica do século XIX, e ficamos apenas com o conceito do ferimento enquanto uma punição" (N. T.).

13 Traduzido para o português brasileiro sob o título A Águia da Nona, e editado pela Editora Record (N. T.).

\section{Referências}

ALCOTT, Louisa May. Little Men. Boston: Roberts Brothers, 1871.

ALCOTT, Louisa May. Jack and Jill. Boston: Roberts Brothers, 1879.

AVERY, Gillian. Nineteenth Century Children: heroes and heroines in English children's stories. London: Hodder, 1965.

BARRIE, James Matthew. Peter and Wendy. London: Hodder, 1911.

BLYTON, Enid Mary. Third Year at Malory Towers. London: Methuen, 1948.

BLYTON, Enid Mary. Upper Fourth at Malory Towers. London: Methuen, 1949.

BLYTON, Enid Mary. Last Term at Malory Towers. London: Methuen, 1951.

BRATTON, Jacky. The Impact of Victorian Children's Fiction. London: Croom Helm, 1981.

BRENT-DYER, Elinor. Eustacia Goes to the Chalet School. London: Chambers, 1930. BRENT-DYER, Elinor. Stepsisters for Lorna. London: Temple, 1948.

BRUCE, Dorita Fairlie. The Girls of St Brides. Oxford: Oxford University Press, 1923. BURNETT, Frances Hodgson. The Secret Garden. New York, N.Y.: Stokes, 1911.

COOLIDGE, Susan (Pseudônimo de Sarah Chauncey Woolsey). What Katy Did. Boston: Roberts Brothers, 1872.

DICKENS, Charles. A Christmas Carol. London: Chapman \& Hall, 1843.

DODGE, Mary Mape. Hans Brinker, or The Silver Skates: a story of life in Holland. Philadelphia: George Jacobs, 1865.

EWING, Juliana Horatia. Convalescence. London. SPCK, 1883.

EWING, Juliana Horatia. Laetus Sorte Mea, or The Story of a Short Life. London: SPCK, 1885.

GATTY, Alfred. Aunt Judy's Tales. London: Bell \& Daldy, 1859.

HART, Elizabeth Anna. Daisy's Dilemmas. London: Cassell, 1900.

Educação \& Realidade, Porto Alegre, v. 38, n. 4, p. 1053-1068, out./dez. 2013.1067

Disponível em: <http://www.ufrgs.br/edu_realidade> 
A Representação da Deficiência em Livros Infantis

HOLMES, Martha Stoddard. Fictions of Affliction: physical disability in Victorian culture. Ann Arbor: University of Michigan Press, 2004.

JACBERNS, Raymond. A Schoolgirl's Battlefield. London: Chambers, 1910.

KEARY, Annie. Mia and Charlie. London: Warne, 1856.

KEARY, Annie. Sidney Grey. London: Warne, 1857.

KEARY, Annie. Father Phim. London: Warne, 1875.

KEITH, Lois. Take Up Thy Bed and Walk: death, disability and cure in Classic fiction for girls. London: The Women's Press, 2001.

MARTINEAU, Harriet. The Crofton Boys. London: Routledge, 1841.

MOLESWORTH, Mary Louisa. The Oriel Window. London: Leslie Brooke, 1896.

MULOCK, Dinah. The Little Lame Prince, and His Travelling Cloak. London. Daldy, Isbister \& Co, 1875.

PORTER, Eleanor. Pollyanna. Boston: Page, 1911.

REED, Talbot Baines. The Fifth Form at St. Dominics'. London: Religious Tract Society, 1887.

SPYRI, Johanna. Heidi. Heidi's Lehr und Wanderjahre. Gotha: Friedrich Andreas Perthes, 1880.

SUTCLIFF, Rosemary. The Eagle of the Ninth. Oxford: Oxford University Press, 1954.

SUTCLIFF, Rosemary. Warrior Scarlet. Oxford: Oxford University Press, 1958.

WELLS, Rosemary. The Little Lame Prince. London: Picture Lions, 1992.

WIGGIN, Kate Douglas. The Birds' Christmas Carol. Boston: Houghton Mifflin, 1891.

YONGE, Charlotte Mary. The Two Guardians. London: Macmillan, 1852.

YONGE, Charlotte Mary. The Heir of Redclyffe. London: Parker, 1853.

YONGE, Charlotte Mary. Heartsease, or The Brother's Wife. London. Macmillan, 1856.

YONGE, Charlotte Mary. The Daisy Chain, or Aspirations. London: Parker, 1856.

YONGE, Charlotte Mary. Hopes and Fears, or Scenes from the Life of a Spinster. London: Parker, 1860.

YONGE, Charlotte Mary. The Clever Woman of the Family. London: Macmillan, 1865.

YONGE, Charlotte Mary. The Pillars of the House, or Under Wode, Under Rode. London: Macmillan, 1873.

Ann Dowker é professora e pesquisadora no Departamento de Psicologia Experimental da Universidade de Oxford. É membro do conselho do projeto Every Child Counts. Trabalha com pesquisadores da França, Itália, Polônia, Brasil, China e Irã sobre jogos infantis com linguagem e uso espontâneo de rima e metáforas. Colabora com pesquisadores da Finlândia e dos Estados Unidos sobre incapacidades de aprendizagem matemática.

E-mail: ann.dowker@psy.ox.ac.uk

Tradução: Edgar Roberto Kirchof

1068 Educação \& Realidade, Porto Alegre, v. 38, n. 4, p. 1053-1068, out./dez. 2013 Disponível em: <http://www.ufrgs.br/edu_realidade> 